\title{
Incidental cholecystojejunal fistula: a rare complication of gall stone disease
}

\begin{abstract}
Cholecystoenteric fistula is a rare complication of gallstone disease and difficult to diagnose preoperatively. Among Cholecystoenteric fistula, cholecystojejunal fistulae are even rarer and only a few case reports have been published on it. Here we report a case of a 60 -year male patient with cholecystojejunal fistula diagnosed intraoperatively while performing laparoscopic cholecystectomy. Fundus of the gall bladder was found to be communicating with proximal jejunum. We conclude that in elderly patients if the ultrasonography shows features of contracted gall bladder in presence of large gall stones one should consider an option of getting a computed tomography scan done preoperatively.
\end{abstract}

Keywords: cholecystoenteric, cholecystojejunal, fistula, gall-stones, cholecystitis
Volume 8 Issue 4 - 2020

\author{
Vipul K Srivastava,' Shilpi Roy,' Ramniwas \\ Meena, ${ }^{2}$ Rahul Khanna ${ }^{2}$ \\ 'Resident, Department of General Surgery, Institute of Medical \\ Sciences, India \\ ${ }^{2}$ Professor, Department of General Surgery, Institute of Medical \\ Sciences, India
}

Correspondence: Dr. Ramniwas Meena, Professor

Department of General Surgery, Institute of Medical Sciences

Banaras Hindu University, Varanasi-221005, UP, India,

Tel+919935 I41697, Email drramniwsmeena@gmail.com

Received: October 25, 2020 | Published: December 17, 2020

\section{Introduction}

Cholecystoenteric fistula (CEF) was first described by Courvoisier in 1890. They are a rare complication of gallstone disease and are formed due to ongoing inflammation. ${ }^{1}$ They are bilioenteric type of Internal Biliary fistula which is rare to find. Preoperative diagnosis of CEF is difficult to make with pneumobilia being the most common radiological finding. ${ }^{2}$ So here we report a rare case of cholecystojejunal fistula. Only a few case reports have been published on cholecystojejunal fistula. ${ }^{3,4}$

\section{Case report}

A 60-year male presented to General Surgery outpatient department with complaints of recurrent pain in right upper abdomen for past two year and multiple episodes of bilious vomiting from past ten days. There was no history of fever, yellowish discoloration of eyes and urine, hematemesis, melena or significant weight loss. Physical examination revealed mild tenderness on the right hypochondriac and umbilical regions without any palpable lump. Blood investigations were within normal limits without any evidence of leukocytosis or deranged liver function tests. Abdominal ultrasound revealed thick wall contracted gallbladder with a single $4.8 \mathrm{~cm}$ stone inside the gallbladder. Patient was undertaken for laparoscopic cholecystectomy but due to dense adhesions along with the contracted gallbladder procedure was converted into open laparotomy through a subcostal incision. Fundus of the gallbladder was connected with proximal jejunum through a fistulous tract Figure 1. Gallbladder along with the stone and entire fistulous tract was excised and cut sections of jejunum were primarily repaired. A suction drain was put which had the output of $50 \mathrm{ml}$ sero-sanguineous fluid which gradually reduced and was removed on post-operative day three. Patient had stable vitals and was discharged on seventh post-operative day. Histopathology confirmed the diagnosis of Chronic Cholecystitis with Cholelithiasis. The excised fistulous tract showed features of chronic inflammation.

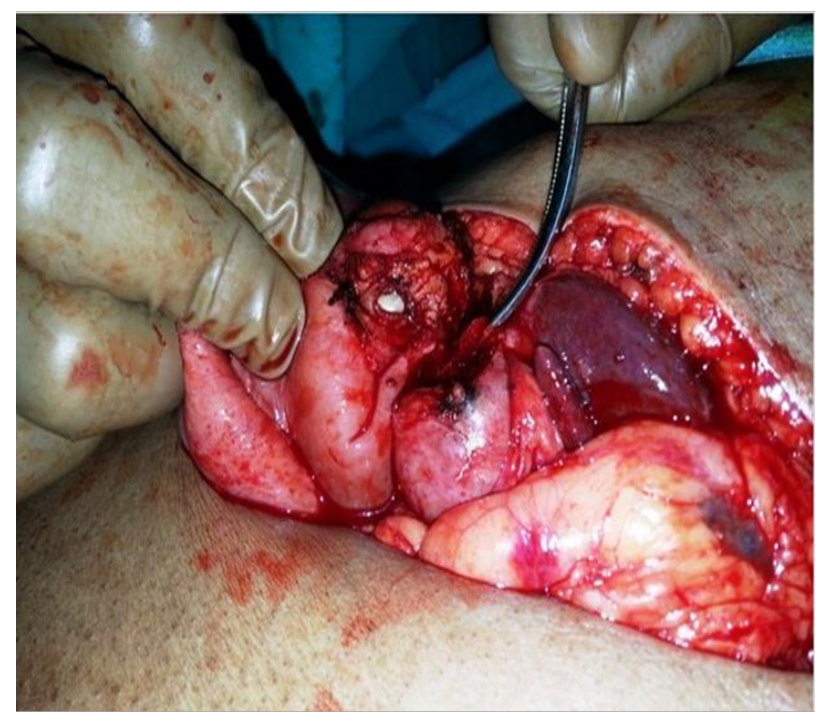

Figure I Image showing fistulous opening between gallbladder and jejunum.

\section{Discussion}

Cholecystoenteric fistulae (CEF) are not so common with the incidence of $0.15 \%$ to $5 \%$ of the biliary disease. ${ }^{5}$ Among CEF most common is cholecystoduodenal fistula accounting for $80 \%$ of the cases followed by cholecystocolonic and cholecystogastric fistulae. ${ }^{6}$ In the literature only a few case reports of cholecystojejunal fistulae have been described. ${ }^{3,4}$ The major cause for fistula formation is the inflammatory reaction which causes erosion between the gallbladder and the visceral organs. This inflammatory reaction may be due to the Cholecystitis, peptic ulcer, malignancy, etc. Other mechanism which leads to fistula formation is the pressure necrosis from large stone within the gallbladder lumen ${ }^{7}$ which seems to be more appropriate 
cause in our case as the stone size was very large $(4.8 \mathrm{~cm})$. Preoperative diagnosis of CEF is a challenging task and was possible only in $31 \%$ of the patients in a study done by $\mathrm{Li}$ et al. ${ }^{8} \mathrm{CEF}$ presents with vague symptoms as abdominal pain, diarrhea, vomiting, etc. which are nonspecific or may sometimes present with gall stone ileus. Radiological finding may only be pneumobilia in most of the cases. ${ }^{2}$ So for a surgeon preoperative diagnosis of CEF remains a challenging task which may lead to performing unanticipated complex and lengthy procedures. Also there is possibility of catastrophic damage to patient as many vital structures lie posterior to the gallbladder.

Therefore it is mandatory that any case of CEF be diagnosed preoperatively for appropriate management. Open cholecystectomy along with excision and closure of the fistula is the adequate treatment for CEF as mentioned by Glenn et al. ${ }^{9}$ Adhesions and multiple fistulae increase the chances of open surgery. However with the new advancements in laparoscopy some authors have reported that adequate treatment is possible by laparoscopic techniques also but it requires expertise. ${ }^{4}$ The rate of conversion to open surgery is still high due to bleeding and inflammation around the gallbladder. ${ }^{10}$ In our case also due to dense adhesions conversion to open procedure was done. We do not advocate our alignment towards certain procedure but intend to express that the surgeon should be well versed with both the procedures and decision of doing an open or a laparoscopic approach should be tailored as per the patient requirements and patient's ability to tolerate the procedure.

\section{Conclusion}

Through this case report we wish to emphasize upon the point that in an elderly patient if the ultrasonography shows features of contracted gall bladder in presence of large gall stones one should consider an option of getting a computed tomography scan done preoperatively. If dense adhesions along with knotting of bowel loops are found around the gall bladder then one should be very careful while proceeding with further dissection with a possibility of CEF in mind.

\section{Acknowledgments}

None.

\section{Conflicts of interest}

None of the authors declares conflicts of interest.

\section{Funding}

None.

\section{References}

1. Abou-Saif A, Al-Kawas F. Complications of gallstone disease: mirrizzi syndrome, cholecystocholedochal fistula, and gallstone ileus. $\mathrm{Am} \mathrm{J}$ Gastroenterol. 2002;97(2):249-254.

2. Singh N, Stempel K. Images in clinical medicine. cholecystoduodenal fistula. $N$ Engl J Med. 1997;336(4):266.

3. Glaysher MA, Cruttenden-Wood D, Szentpali K. A rare cause of upper gastrointestinal haemorrhage: ruptured cystic artery pseudoaneurysm with concurrent cholecystojejunal fistula. Int J Surg Case Rep. 2014;5(1):1-4.

4. Jung HI, Ahn T, Cho SW, et al. Incidental cholecystojejunal fistula treated with successful laparoscopic management. Ann Surg Treat Res. 2014;87(5):276-278.

5. Duzgun AP, Ozmen MM, Ozer MV, et al. Internal biliary fistula due to cholelithiasis: a single-centre experience. World $J$ Gastroenterol. 2007;13(34):4606-4609.

6. Shah M, Mori W. A clinico-pathological study of spontaneous internal biliary fistula. Acta Pathol Jpn. 1973;23(2):349-358.

7. Nahrwold DL. Gallstone ileus. In: Cameron JL, editor. Current Surgical Therapy. St Louis, Mo: Mosby Inc; 1998.

8. Li XY, Zhao X, Zheng P, et al. Laparoscopic management of cholecystoenteric fistula: a single-center experience. $J$ Int Med Res. 2017;45(3):1090-1097.

9. Glenn F, Reed C, Grafe WR. Biliary enteric fistula. Surg Gynecol Obstet.1981;153(4):527-532.

10. Angrisani L, Corcione F, Tartaglia A, et al. Cholecystoenteric fistula (CF) is not a contraindication for laparoscopic surgery. Surg Endosc. 2001;15(9):1038-1041. 